\title{
Handling of Cadavers in a Mortuary amidst COVID-19 Pandemic
}

\author{
Rimpi Gupta ${ }^{1}$ \\ ${ }^{1}$ Department of Anatomy, Kalpana Chawla Government Medical \\ College, Karnal, Haryana, India \\ ${ }^{2}$ Department of Forensic Medicine and Toxicology, Bhagat Phool \\ Singh Government Medical College For Women, Sonipat, Haryana, \\ India
}

Ann Natl Acad Med Sci (India):2020;56:224-226

\author{
Shveta Swami ${ }^{1}$ Swati Bansal ${ }^{1} \quad$ Neha Gaur
}

\begin{abstract}
Address for correspondence Rimpi Gupta, MBBS, MS, Department of Anatomy, Kalpana Chawla Government Medical College, Karnal, Haryana 132001, India (e-mail: dr.rimpigupta15@gmail.com).
\end{abstract}

\begin{abstract}
Keywords

- dead bodies

- mortuary

- COVID-19

- health care professionals

Coronavirus disease 2019 (COVID-19) caused by severe acute respiratory distress syndrome coronavirus 2 (SARS-CoV-2) has been declared as a pandemic by the World Health Organization (WHO). This new disease is a challenge for the managers of health care facilities and mortuaries. It has impacted the practice of whole medical community. Though there is literature available on route of transmission of virus and time span for which virus is active on surfaces but there is no data available on how long the virus lives in and is active on the surface of a dead body. Thus, the health care professionals who handle cadavers and their specimens should use professional judgment to determine if a decedent had signs and symptoms compatible with COVID-19 during life and if autopsy is mandatory. Ministry of Health and Family Welfare and Centre for Disease Control \& Prevention (CDC) have issued guidelines on dead body management and collection of postmortem specimens which should be observed in mortuary area and laboratories to limit the spread of disease among health care workers.
\end{abstract}

\section{Introduction}

Coronavirus disease 2019 (COVID-19) is an infectious disease caused by severe acute respiratory distress syndrome coronavirus 2 (SARS-CoV-2), a member of the betacoronavirus family. ${ }^{1,2}$ It was first identified in December 2019 in Wuhan and since then had spread globally. World Health Organization (WHO) declared it a pandemic on March 11, $20200^{2,3}$ As it is caused by a novel coronavirus, the exact pathophysiology of the disease, its course, and therapeutics are not fully understood, as of now. As a result it has led to considerable anxiety and panic not only in general public but also among the health care workers. ${ }^{4}$ However, from a living person, the virus spreads between people during close contact (i.e., within approximately 6 feet), often via small droplets produced by coughing, sneezing, and talking. This route of infection is not a concern when handling human remains or performing postmortem procedures. People may also become infected by touching a contaminated surface and then touching their face. ${ }^{5-7}$ The asymptomatic carriers of the virus tend not to get tested and contribute significantly to the spread of disease. ${ }^{8,9}$ The standard method of diagnosis is by real time reverse transcriptase polymerase chain reaction from a nasopharyngeal (NP) swab. Recommended measures to prevent infection include frequent hand washing, maintain physical distance from others especially from those with symptoms, quarantine, covering coughs, and keeping unwashed hands away from face. ${ }^{10,11}$ Till date, there are no available vaccine nor specified antiviral treatment for COVID-19. ${ }^{5}$ This new disease is a challenge for the whole medical community including paramedics, and they are at significant risk of getting infection if standard infection prevention and control measures are not taken.
DOI https://doi.org/ 10.1055/s-0040-1721555 ISSN 0379-038X. (c) 2020. National Academy of Medical Sciences (India).

This is an open access article published by Thieme under the terms of the Creative Commons Attribution-NonDerivative-NonCommercial-License, permitting copying and reproduction so long as the original work is given appropriate credit. Contents may not be used for commercial purposes, or adapted, remixed, transformed or built upon. (https://creativecommons.org/licenses/by-nc-nd/4.0/).

Thieme Medical and Scientific Publishers Pvt. Ltd. A-12, 2nd Floor, Sector 2, Noida-201301 UP, India 
According to WHO, dead bodies are generally not infectious except in cases of hemorrhagic fevers (Ebola, Marburg) and cholera. Only the lungs of the patients with pandemic influenza, if handled improperly during autopsy can be infectious. WHO further adds that any body fluids leaking from orifices in the cadavers must be contained. There is no need to disinfect the body before transfer to the mortuary area. ${ }^{12}$

The first incidence of COVID-19 being transmitted from a dead body to a medical professional in a Forensic Medicine unit occurred in Thailand on April 14, 2020. ${ }^{13}$ However, in India, no such case has been reported till date.

Although not much is known about how long the novel coronavirus can live in dead bodies, yet "anyone coming in contact with a COVID-19 positive body alive or dead should be using personal protective equipment (PPE) to prevent exposure" Health policy expert Summer Johnson McGee of the University of New Haven told BuzzFeed News by e-mail. Coroners are increasingly being asked to conduct investigations into the cause of death for patients who had died and were not tested. She further added that autopsies and the subsequent investigations pose real risks for coroners to get infected by COVID-19. ${ }^{14}$

The infectious disease specialist and assistant professor at the University of Alberta, Dr. Schwartz said, "It would be possible that the virus could persist and remain infectious in or on the body of someone who has died."15

\section{Guidelines on Dead Body Management in the Mortuary}

Government of India, Ministry of Health and Family Welfare (MoHFW) Director General of Health Services (EMR Division) has issued guidelines on dead body management on March 15, 2020 based on the current epidemiological knowledge about COVID-19. According to the guidelines, all the staff identified to handle dead bodies in the mortuary should be trained in the infection prevention control practices and observe following standard precautions. ${ }^{16,17}$

1. Hand hygiene is the first and foremost preventive measure to be followed before and after the interaction with the dead body.

2. Use of PPE (e.g., water-resistant apron, gloves, masks, and eyewear).

3. Safe handling of sharps.

4. Used equipments should be autoclaved or decontaminated with disinfectant solutions in accordance with established infection prevention control measures.

5. All soiled/used linen should be handled with standard precautions, put in the bio-hazard bag and the outer surface of the bag disinfected with hypochlorite solution.

6. All medical waste must be disposed of in accordance with biomedical waste management rules.

7. All the surfaces of mortuary like floor, mortuary table, door handles should be wiped with $1 \%$ sodium hypochlorite solution, allow a contact time of 30 minutes, then allow to dry.
8. Dead bodies should be stored in cold chambers maintained at approximately $4^{\circ} \mathrm{C}$.

9. Embalming of dead body should not be allowed to avoid excessive manipulation of the body.

10. Adults more than 60 years of age and immunosuppressed persons should not directly interact with the body.

\section{Precautions Taken during Autopsy Procedure}

Standard precautions, contact precautions, and airborne precautions with eye protection (goggles or a face shield) should be followed during autopsy. These are consistent with the existing guidelines for safe work practices in the autopsy setting. ${ }^{17,18}$

\section{Personal Care}

1. The number of forensic experts and support staff in the autopsy room should be limited and well trained in infection prevention control practices.

2. Mortuary staff preparing the body (e.g., washing the body, tidying hairs, trimming nails, or shaving) should wear appropriate PPE.

3. The team should use full complement of PPE (coveralls, head cover, shoe cover, N-95 masks, goggles, face shield).

4. Only one body cavity at a time should be dissected.

5. Allow only one person to cut at a given time.

6. A logbook including names, dates, and activities of all workers participating in the postmortem and cleaning of the autopsy suite should be kept to assist in future follow-up.

\section{Recommended Equipments to Be Used Are}

1. Aerosol generating procedures such as use of an oscillating bone saw should be avoided for known or suspected COVID-19 cases. Consider using hand shears as an alternative cutting tool. If an oscillating saw is used, attach a vacuum shroud to contain aerosols.

2. Round-ended scissors should be used.

3. PM40 or any other heavy duty blades with blunted points to be used to reduce prick injuries.

4. Unfixed organs must be held firm on the table and sliced with a sponge-care should be taken to protect the hand.

5. Needle should not be resheathed after fluid samplingneedles and syringes should be placed in sharp bucket.

\section{Engineering Control Recommendations for Autopsy}

1. Perform autopsy in an adequately ventilated room, i.e., at least natural ventilation with at least $160 \mathrm{~L} / \mathrm{s} /$ patient air flow.

2. Room should have a minimum of six air changes per hour $(\mathrm{ACH})$ for existing structures and $12 \mathrm{ACH}$ for new structures.

3. Negative pressure to be maintained in the mortuary.

4. Room should have air exhausted directly outside or through a high efficiency particulate aerosol filter. 


\section{PPE Recommendations for Autopsies}

1. Double surgical gloves should be worn.

2. Fluid-resistant isolation gown.

3. Waterproof apron.

4. Goggles/face shield.

5. Disposable N-95 respirator.

6. Shoe covers.

7. Surgical cap.

\section{Recommended Biosafety and Infection Control Practices during Specimen Collection}

Following are the CDC, Government of India guidelines regarding collection and submission of postmortem specimen from diseased (persons with known or suspected COVID-19).18 NP swab is the preferred choice for upper respiratory tract swab-based SARS-CoV-2 testing. Collection of NP swab specimens from a dead person will not induce coughing or sneezing, a negative pressure room is not required, however, standard precautions should be observed. Biosafety cabinet for handling and examining smaller specimens should be used.

The following PPE should be worn at a minimum:

- Wear nonsterile nitrile gloves.

- If there is risk of cut or puncture wounds, wear heavy duty gloves over the nitrile gloves.

- Wear long sleeved impermeable gown.

- Used plastic face shield/goggles.

\section{Biomedical Waste Management and Environmental Cleaning}

- After the procedure, discard the PPE in the appropriate laundry or waste receptacle. Reusable PPE like face shield or googles, must be disinfected. Wash hands with soap and water for 20 seconds. Avoid touching face. ${ }^{17,18}$

- The body of the deceased should be disinfected with $1 \%$ sodium hypochlorite and placed in a body bag, the exterior of which will again be decontaminated with $1 \%$ sodium hypochlorite solution.

- Autopsy table to be disinfected as per standard protocol.

- Keep ventilation system active while cleaning is conducted.

- Do not use water under pressure for cleaning as it may re-aerosolize infectious material.

- Dispose off human tissues according to routine procedures.

\section{Disinfect/Autoclave Instruments}

The body thereafter can be handed over to the relatives.

\section{Conflict of Interest}

None declared.

\section{References}

1 Coronavirus disease 2019 (COVID-19)-symptoms and causes. Mayo Clinic 2020. Available at: Mayo Clinic.org/diseases-conditions/coronavirus/symptoms-causes/syc-20479963. Accessed November 18, 2020
2 World Health Organization. Available at: http://www.who. int/dg/speeches/detail/who-director-general-s-openingremarks-at-the -media-briefing-on-covid-19. Accessed March 11,2020

3 Hui DSI, I Azhar E, Madani TA, et al. The continuing 2019-nCoV epidemic threat of novel coronaviruses to global health-the latest 2019 novel coronavirus outbreak in Wuhan, China. Int J Infect Dis 2020;91:264-266

4 Srinivasan R, Gupta P, Rekhi B, et al. Indian academy of cytologists national guidelines for cytopathology laboratories for handling suspected and positive COVID-19 (SARS-COV-2) patient samples. J Cytol 2020;37(2):67-71

5 World Health Organization. Q \& A on coronaviruses. Available at: https://www.who.int/news-room/q-a-detail/coronavirus-disease-covid-19. Accessed November 18, 2020

6 Centers for Disease Control and Prevention. Coronavirus Disease 2019 (Covid-19). How does the virus spreads. Available at: cdc. gov/coronavirus/2019-ncov/faq.html. Accessed November 18, 2020

7 European Centre for Disease Prevention and Control. Q \& A on COVID-19. Available at: ecdc.europa.eu/en/covid-19/questions-answers. Accessed November 18, 2020

8 Bai Y, Yao L, Wei T, et al. Presumed asymptomatic carrier transmission of COVID-19. JAMA 2020;323(14):1406-1407

9 "China Reveals 1541 symptom free virus cases under pressure". Available at: www.bloomberg.com. Accessed March 31, 2020

10 World Health Organization. Advice for public. Available at: https://www.who.int/news-room/q-a-detail/coronavirus-disease-covid-19. Accessed November 18, 2020

11 Guidance for social distancing for everyone in the UK. Available at: https://www.gov.uk/government/publications/ covid-19-guidance-on-social-distancing-and-for-vulnerablepeople/guidance-on-social-distancing-for-everyone-in-theuk-and-protecting-older-people-and-vulnerable-adults [now withdrawn]

12 World Health Organization. Infection prevention and control during healthcare when COVID-19 is suspected: interim guidance, January 25, 2020. Available at: http://www. who.int/publication-detail/infection-prevention-and-control-during-health-care-when novel-coronavirus-(nCoV)-infection-is-suspected-20200125. Accessed April 22, 2020

13 Won S, Viroj W. COVID-19 in forensic medicine unit personnel: observation from Thailand.J Forensic Leg Med 2020;72:101964

14 Buzzfeed News. Available at: https://www.buzzfeednews. com/article/danvergano/coronavirus-spread-deadbody-coroner. Accessed April 13, 2020

15 CBC News. Are dead bodies contagious? Your COVID-19 Questions Answered. Available at: http:/www. cbc.ca/news/ covid-questioned-answered-bodies-1.5535139. Accessed April 17,2020

16 COVID-19. Guidelines on dead body management. Available at: https:/ www.mohfw.gov.in/Pdf/1584423700568-COVID 19 guidelines on dead body management. Accessed March 15, 2020

17 World Health Organization. Infection prevention and control for the safe management of a dead body in the context of COVID-19. Interim Guidance. Available at: http:/apps.who.int/ iris/handle/10665/331538. Accessed March 24, 2020

18 Centre for Disease Control and Prevention (CDC). Collection and submission of postmortem specimens from deceased persons with known or suspected COVID-19. Interim Guidance. Available at: https:/ www.cdc.gov/coronavirus/2019-ncov/ hcp/guidance-postmortem-specimens.html. Accessed April 22, 2020 